\title{
Hydrogen permeable membranes based on niobium foils coated with layer of tungsten and molybdenum in niobium solid solution characteristics research.
}

\author{
* Panichkin A. V. \\ Institute of Metallurgy \\ and Ore Beneficiation \\ (IMOB) JSC, 050010, \\ Republic of \\ Kazakhstan, Almaty
}

\author{
Kenzhaliyev B. K. \\ Institute of Metallurgy \\ and Ore Beneficiation \\ (IMOB) JSC, 050010, \\ Republic of \\ Kazakhstan, Almaty
}

\section{Derbisalin A. M.}

Institute of Metallurgy and Ore Beneficiation (IMOB) JSC, 050010, Republic of Kazakhstan Almaty

NJSC "Kazakh National

Research Technical

University named after

K.I. Satpayev, 050013, Republic of Kazakhstan, Almaty

\author{
Mamayeva A. A. \\ Institute of Metallurgy \\ and Ore Beneficiation \\ (IMOB) JSC, 050010, \\ Republic of Kazakhstan, \\ Almaty
}

Dzhumabekov D. M. Institute of Metallurgy and Ore Beneficiation (IMOB) JSC, 050010, Republic of Kazakhstan, Almaty

\begin{abstract}
Paper presents the results of measuring the hydrogen permeability of $\mathbf{4 0} \boldsymbol{\mu m}$ niobium foil membranes, on one side coated with a layer of a solid solution of tungsten in niobium or molybdenum in niobium. The measurements were carried out in a hydrogen atmosphere of technical purity with a smooth temperature decrease followed by isothermal aging and under conditions of cyclic temperature variation. It is shown that the degree of purity of argon used for magnetron sputtering has the greatest influence on the hydrogen permeability of composite niobium membranes. As a result of $1 \mathrm{um}$ thick molybdenum in niobium ( $\mathrm{Nb}$ - $15 \mathrm{wt} \% \mathrm{Mo}$ ) and tungsten in niobium $(\mathrm{Nb}-10 \mathrm{wt} \% \mathrm{~W})$ solid solution deposition on the surface of a niobium membrane, the average value of their hydrogen permeability decreases, while a number of samples demonstrated a significant increase of durability. When the Nb - 15 mass \% Mo layer is deposited in purified argon, the hydrogen permeability of the membranes increases by 15-20 times compared to pure niobium and up to 30 times in comparison with the membranes deposited in technical purity argon and reaches $68 \mathrm{~mol} / \mathrm{s}^{*} \mathrm{~m}^{*} \mathbf{P a}^{0.5}$, however, lifetime of membranes before destruction is dramatically reduced and ranges from 13 to $280 \mathrm{~s}$., with a rapid decrease in hydrogen permeability due to their oxidation. In case of $\mathrm{Nb}-10 \mathrm{wt} . \% \mathrm{~W}$ films deposition using additionally purified argon, the hydrogen permeability of membranes rises more than 20-times and reaches a level of $30 \mathrm{~mol} / \mathrm{s}^{*} \mathrm{~m}^{*} \mathrm{~Pa}^{0.5}$, however, the membrane operation time is shortened to 25-320 s. The hydrogen "superconductivity" effect found in niobium composition membranes requires further studies. The use of films of solid solutions of molybdenum or tungsten in niobium, as buffer layers between the membrane and palladium layer, is proposed.
\end{abstract}

Keywords-composite membrane; niobium; solid solution; coating; hydrogen permeability; dilatation

\section{INTRODUCTION}

One of the most promising ways to extract hydrogen from gas mixtures formed during steam conversion is a one-step membrane separation to produce ultrapure hydrogen. However, palladium and its alloys are industrially used as membrane material, but very high cost limits the spread of this method. In this regard, development of the hydrogen industry requires the development of new highly efficient and inexpensive hydrogen permeable membranes. Metals of the 5-th group, in particular niobium, are substantially cheaper than palladium and are characterized by high hydrogen-absorbing capacity [14]. This makes it possible to manufacture membranes for hydrogen purification from them, however, due to the high hydrogen embrittlement and activity with such gases as $\mathrm{CO}$, $\mathrm{O} 2, \mathrm{H} 2 \mathrm{O}$ at the hydrogen diffusion temperatures, characteristics of such membranes deteriorate rapidly. As a result of interaction with reactive gases, as well as surface segregation of oxygen dissolved in the lattice, at the operating temperatures (>520 K), niobium surface is covered with an oxide film, which hampers the catalytic dissociation of hydrogen molecules necessary for hydrogen absorption [1-5].

It means, it's necessary to protect the membrane surface from oxidation. It is believed that the most promising coating for niobium membrane is palladium or its alloys up to several microns thick [6-14], performing both protective and catalytic functions. However, problems facing the use of niobium composite membranes are: low thermal stability of the palladium coating, insufficient obstacle to transition to brittle condition of niobium membranes at operating temperatures. Thus, it is necessary to search for other ways to increase the 
corrosion resistance of niobium membranes and to prevent their destruction during the transition to a brittle state.

As follows from the experimental data presented in [15], thin layer of solid solutions of tungsten and molybdenum in niobium (Nb-18 at\% Mo, Nb-16.5 at\% W) are magnetron sputtered on the niobium surface, it's increases its corrosion resistance at $550^{\circ} \mathrm{C}$ in the ordinary atmosphere at a residual pressure of $\sim 100 \mathrm{~Pa}$ in 110 and 38 times, respectively. In this case, the study of the hydrogen permeability of such membranes and their behavior upon contact with hydrogen is promising.

\section{EXPERIMENTAL METHOD}

To prepare the membranes, $40 \mu \mathrm{m}$ thick JSC Ulba Metallurgical Plant, niobium (NbW0) foils were used. After ionic cleaning, thin films of solid solutions, based on niobium were applied to the $120 \times 120 \mathrm{~mm}$ foil surface by magnetron sputtering. For this purpose, a magnetron sputtering device equipped with an ion source APEL-IS-21CELL and magnetrons APEL-MRE100 was used. Ionic purification was carried out with argon at an operating voltage $3.00 \mathrm{kV}$, current 60-80 $\mathrm{mA}$, pressure $3 * 10^{-1} \mathrm{~Pa}$, and 20 minute duration. Magnetron sputtering was carried out for 20 minutes using a sectional target $\varnothing 100 \mathrm{~mm}$ at a work current $2.01 \mathrm{~A}, 300 \mathrm{~V}$, pressure $2-4.5^{*} 10^{-1} \mathrm{~Pa}$. The distance between the substrate and the target was $200 \mathrm{~mm}$. Magnetron sputtering was carried out using $99.993 \%$ purity argon and after additional purification by passing through a layer of a titanium sponge heated up to $800^{\circ} \mathrm{C}$. Composition and thickness of the obtained tungsten and molybdenum solid solutions in niobium were determined on a JEOL JXA-8230 microprobe analyzer.

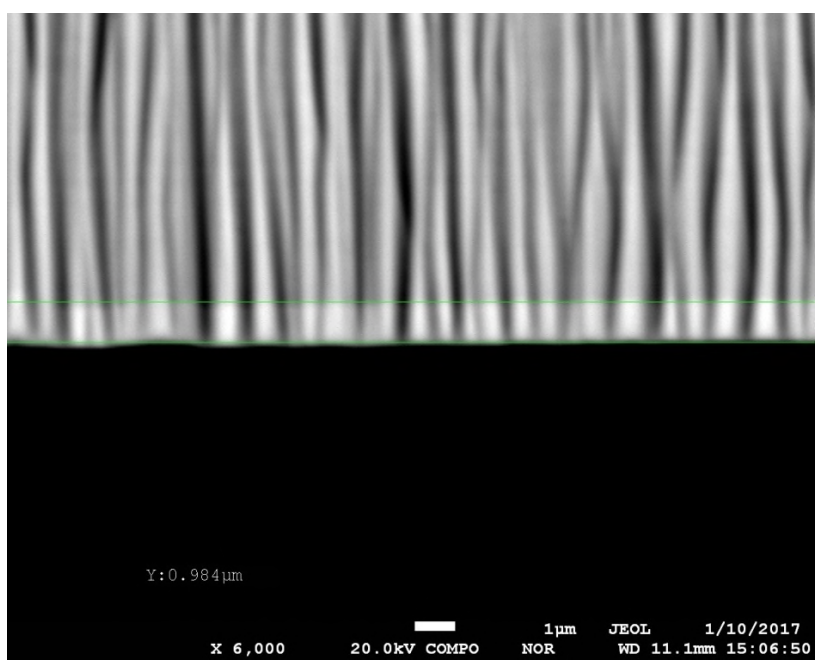

Fig. 1. A layer of a solid solution of tungsten in niobium on the surface of a niobium foil. (Cross section).

Experiments to determine the hydrogen permeability of $\varnothing 100 \mathrm{~mm}$ niobium-based composite membranes were carried out using the method and on the equipment described in [16]. Measurement of hydrogen permeability was carried out at an excess pressure of hydrogen of grade B $(99.95 \%)$ at 300,400 , $500,700 \mathrm{kPa}$ and at the beginning of the experiment at 550 , $565,575,585{ }^{\circ} \mathrm{C}$ under conditions of uniform temperature decrease followed by isothermal aging and under cyclic temperature changes with oscillations up to $\sim \pm 20^{\circ}$ with a period of $\sim 600 \mathrm{~s}$. The choice of experimental conditions is based on the optimal operating conditions found for membranes based on niobium foils [17]. Simultaneously with the value of the gas flow, the temperature of the base was fixed, to which the membrane adhered. The tests were carried out before the membrane burst. Hydrogen was additionally subjected to purification from moisture by passing it through chilled to $-40{ }^{\circ} \mathrm{C}$ aluminum chips.

\section{EXPERIMENTAL PART}

With the selected modes of magnetron sputtering of the sectional targets, layers of $\mathrm{Nb}-10 \mathrm{wt} \% \mathrm{~W}, \mathrm{Nb}-15 \mathrm{wt} \% \mathrm{Mo}$ were deposited on the surface of the niobium foils. Their thickness was $1 \pm 0.1 \mu \mathrm{m}$.

The results of measuring the hydrogen permeability of the resulting composite membranes are presented in Tables I and II. Under the experimental conditions, with a smooth temperature decrease, the hydrogen permeability of the membranes first increases, reaching a maximum in 100-300 s. from the moment of membrane contact with hydrogen. In the future, it decreases to certain values, the value of which under isothermal holding conditions does not significantly decrease with time. In some cases, the destruction of the membrane occurs even before the stabilization of hydrogen permeability.

TABLE I - HYDROGEN PERMEABILITY OF COMPOSITE MEMBRANES NB - 15 $\mathrm{WT} \% \mathrm{MO}$

\begin{tabular}{|c|c|c|c|c|c|c|}
\hline № & $\begin{array}{c}\mathrm{H}_{2} \\
\text { pressure, } \\
\mathrm{KPa}\end{array}$ & $\begin{array}{l}\text { Temp. } \\
\text { change } \\
\text { mode }\end{array}$ & $\begin{array}{l}\mathrm{T}_{\text {st. }}, \\
{ }^{\circ} \mathrm{C}\end{array}$ & $\mathrm{T}_{\text {set, }}{ }^{\circ} \mathrm{C}$ & $\begin{array}{c}\mathrm{H}- \\
\text { permability, } \\
\mathrm{mol} / \mathrm{s} \cdot \mathrm{m} \cdot \mathrm{Pa}^{0.5}\end{array}$ & $\begin{array}{c}\text { Period } \\
\text {, sec }\end{array}$ \\
\hline \multicolumn{7}{|c|}{ Magnetron sputtering in Ar 99,993\% } \\
\hline 1 & 700 & \multirow{5}{*}{ Cyclic } & 560 & $\begin{array}{l}537- \\
545\end{array}$ & $\begin{array}{c}\text { from } 0,2 \text { to } \\
1,3\end{array}$ & 1800 \\
\hline 2 & 300 & & 575 & $\begin{array}{c}555- \\
575\end{array}$ & $\begin{array}{c}\text { from } 0,05 \text { to } \\
2\end{array}$ & 8200 \\
\hline 3 & \multirow[b]{2}{*}{400} & & 575 & $\begin{array}{c}555- \\
576\end{array}$ & $\begin{array}{c}\text { from } 1,2 \text { to } \\
3,6\end{array}$ & 3800 \\
\hline 4 & & & 575 & $\begin{array}{l}545- \\
574\end{array}$ & $\begin{array}{c}5,8 \text { after } 200 \\
\mathrm{~s}, \\
1,8-3,1\end{array}$ & 1600 \\
\hline 5 & 500 & & 575 & $\begin{array}{l}545- \\
575\end{array}$ & от 0,2 до 1,3 & 1800 \\
\hline 6 & \multirow{2}{*}{500} & \multirow{2}{*}{$\begin{array}{l}\text { Smooth } \\
\text { cooling } \\
\text { reaching } \\
\text { isotherm }\end{array}$} & 575 & 539 & $\begin{array}{c}300 \text { from } \\
\max .1,9, \\
\text { then } 1,4\end{array}$ & 2400 \\
\hline 7 & & & 585 & 550 & $\begin{array}{c}280 \text { from } \\
\max 3,1, \\
\text { then } 1\end{array}$ & 2700 \\
\hline \multicolumn{7}{|c|}{ Magnetron sputtering in additionally purified argon } \\
\hline 8 & \multirow[b]{2}{*}{500} & \multirow{2}{*}{$\begin{array}{l}\text { Smooth } \\
\text { cooling } \\
\text { reaching } \\
\text { isotherm }\end{array}$} & 585 & $\begin{array}{c}572 \\
\text { break }\end{array}$ & $\begin{array}{c}\text { reduce from } \\
18 \text { to } 8\end{array}$ & 610 \\
\hline 9 & & & 550 & $\begin{array}{c}536 \\
\text { break }\end{array}$ & $\begin{array}{l}120 \text { from } \\
\text { max. } 68, \\
\text { break } 28\end{array}$ & 325 \\
\hline
\end{tabular}


TABLE II - HYDROGEN PERMEABILITY OF COMPOSITE MEMBRANES NB-10 WT.\% W

\begin{tabular}{|c|c|c|c|c|c|c|}
\hline № & $\begin{array}{c}\mathrm{H}_{2} \\
\text { pressure, } \\
\mathrm{KPa}\end{array}$ & $\begin{array}{l}\text { Temp. } \\
\text { change } \\
\text { mode }\end{array}$ & $\begin{array}{c}\mathrm{T}_{\text {st. }}, \\
{ }^{\circ} \mathrm{C}\end{array}$ & $\mathrm{T}_{\text {set }},{ }^{\circ} \mathrm{C}$ & $\begin{array}{c}\mathrm{H}- \\
\text { permability, } \\
\mathrm{mol} / \mathrm{s} \cdot \mathrm{m} \cdot \mathrm{Pa}^{0.5}\end{array}$ & $\begin{array}{c}\text { Period, } \\
\text { sec }\end{array}$ \\
\hline \multicolumn{7}{|c|}{ Magnetron sputtering in Ar 99,993\% } \\
\hline 1 & 500 & Cyclic & 550 & $\begin{array}{c}510- \\
528\end{array}$ & $\begin{array}{c}\text { From } 0,2 \text { to } \\
1,3\end{array}$ & 1700 \\
\hline 2 & 500 & $\begin{array}{l}\text { Smooth } \\
\text { cooling } \\
\text { reaching } \\
\text { isotherm }\end{array}$ & 550 & 510 & $\begin{array}{c}300 \text { from } \\
\text { max. } 2,7, \\
\text { then } 0,5\end{array}$ & 3600 \\
\hline \multicolumn{7}{|c|}{ Magnetron sputtering in additionally purified argon } \\
\hline 3 & 500 & $\begin{array}{l}\text { Smooth } \\
\text { cooling } \\
\text { reaching } \\
\text { isotherm }\end{array}$ & 575 & $\begin{array}{c}572 \\
\text { (break) }\end{array}$ & $\begin{array}{c}210 \text { from } \\
\text { max } 14,8, \\
\text { then smooth } \\
\text { reduce } 3,6\end{array}$ & 610 \\
\hline 4 & \multirow{2}{*}{500} & \multirow{2}{*}{ Cyclic } & 575 & $\begin{array}{c}538- \\
552\end{array}$ & $\begin{array}{c}150 \text { from } \\
\text { max } 24.5, \\
\text { then } \\
\text { oscillating } \\
\text { from } 2,5 \text { to } \\
10,3\end{array}$ & 2550 \\
\hline 5 & & & 585 & $\begin{array}{c}547- \\
567\end{array}$ & $\begin{array}{l}60 \text { from } \\
\text { max. } 8.8, \\
\text { then smooth } \\
\text { reduce to } 2.1 \\
\text { and increase } \\
\text { to } 3,1\end{array}$ & 1050 \\
\hline
\end{tabular}

In the conditions of cyclic tests, at the initial stage, an increase in hydrogen permeability is observed. Then, after the reduction, it begins to oscillate, while the period of change in hydrogen permeability coincides with the period of change in the temperature of the membrane with a slight shift of the curves relative to each other (Fig. 2). Almost in all the cases considered, the active evolution of hydrogen occurs during the heating of the membrane and slowed down during cooling. A gradual decrease in the average value of hydrogen permeability with time has been observed. With an increase in the excess pressure of hydrogen, especially above $500 \mathrm{kPa}$, there is a tendency to reduce the duration of the membrane until it breaks down. The increase of temperature has less effect on this value. In a number of cases, tests under identical conditions lead to different results on hydrogen permeability and the duration of membrane operation prior to its destruction.

The most significant difference in the value of hydrogen permeability and the duration of membrane operation prior to failure was observed in the case of using additionally purified argon in the magnetron sputtering of solid solution layers. The tables show only those experiments in which the membranes have been operating for a long time. However, during the first 20 seconds more than $70 \%$ of the membranes obtained using purified argon were destroyed. In such membranes, the flow of hydrogen passing through them from the first seconds of the experiment reached $20-70 \mathrm{~mol} / \mathrm{s} * \mathrm{~m} * \mathrm{~Pa}^{0.5}$, then, as a rule, there was a gradual increase in the flow followed by an instantaneous breakthrough. Only a small fraction of the membranes managed to overcome the peak value of hydrogen permeability, after which the decrease in its value began (Fig. 2b).

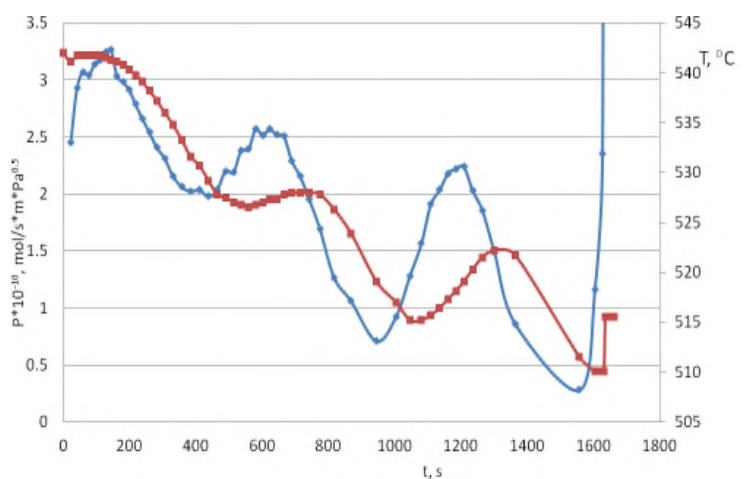

a

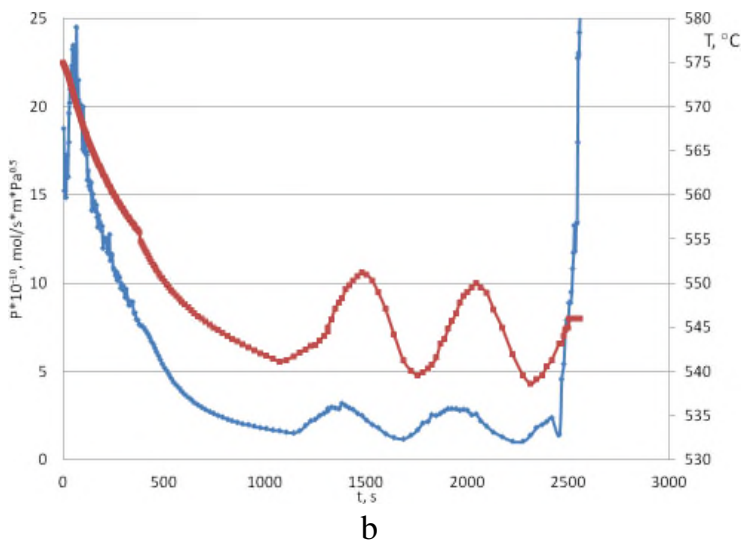

a - 99.993\% purity argon; b - argon after additional purification

Fig. 2. Magnetron sputtering argon purification effect on hydrogen permeability of $40 \mu \mathrm{m}$ thick niobium membranes, deposited with a layer of $\sim 1$ $\mu \mathrm{m}$ solid solution of $\mathrm{Nb}-10 \mathrm{wt} \% \mathrm{~W}$.

A comparison of the obtained data with the results of a change in the hydrogen permeability of $40 \mu \mathrm{m}$ thick niobium foil, given in [17], was made. It follows from the comparison that, as a result of the deposition of layers of a solid solution of $1 \mathrm{um}$ thick molybdenum in niobium ( $\mathrm{Nb}-15 \mathrm{wt} \% \mathrm{Mo})$ and tungsten in niobium ( $\mathrm{Nb}-10 \mathrm{wt} \% \mathrm{~W})$ on a niobium membrane surface using non-purified argon, decrease in the average value of their hydrogen permeability, with a number of samples demonstrating a significant increase in resistance to destruction. When the Nb-15 mass\% Mo layer is deposited in purified argon, the hydrogen permeability of the membranes increases by 15-20 times compared to pure niobium and up to 30 times in comparison with the membranes obtained by depositing in un-purified argon and reaches $68 \mathrm{~mol} / \mathrm{s} * \mathrm{~m} * \mathrm{~Pa}^{0.5}$, however, the period of membrane operation before destruction is dramatically reduced and it's from 13 to $280 \mathrm{~s}$, while a rapid decrease in hydrogen permeability is observed. In case of deposition of $\mathrm{Nb}-10 \mathrm{wt} \% \mathrm{~W}$ films in additionally purified argon, the hydrogen permeability of the membranes rises more than 20 -times and reaches a level of $30 \mathrm{~mol} / \mathrm{s} * \mathrm{~m} * \mathrm{~Pa}^{0.5}$, however, the membrane operation time is shortened to $25-320$ $\mathrm{s}$

A visual examination of the surface of membranes after experiments showed that in all cases the cause of their destruction was dilatation caused by diffusion of hydrogen. 
However, under conditions of cyclic temperature change, the membranes show a significantly longer duration of operation prior to failure in comparison with that observed under conditions of smooth temperature decrease followed by isothermal aging. It was assumed in [17] that this is a consequence of the redistribution of the folds arising during the oscillation of the folds formed during the expansion of the niobium foil as a result of hydrogen dissolution.

Considering the essential dependence of hydrogen permeability of membranes on the presence of impurities in the surface layer, probably oxygen, it can be concluded that the decrease in hydrogen permeability of the developed niobium-based composite membranes over time is mainly a consequence of oxidation of their surface as a result of reaction with active gases contained in hydrogen of technical purity, used in experiments.

\section{CONCLUSION}

Thus, studies of $40 \mu \mathrm{m}$ thick niobium foil membranes coated with layers of solid solutions of Nb-15 wt\% Mo or Nb$10 \mathrm{wt} \% \mathrm{~W}$ have been carried out. It was shown that the value of their hydrogen permeability changes significantly, depending on the impurities deposited in passing with the films of solid solutions during magnetron sputtering. The presence of small impurities leads to a decrease in the hydrogen permeability of the membrane as a whole to values lower than that observed for pure niobium. Films deposited on the surface of a niobium membrane using purified argon transform it into a state of hydrogen "superconductivity". The increasing flow of hydrogen through the membrane leads to its dilatation and, as a rule, to its rapid breakthrough. This raises the task of developing methods for hardening flat membranes to improve their resistance to fracture. Since hydrogen permeability of the investigated composite membranes is rapidly reduced by contact with hydrogen of the investigated composite membranes, due to oxidation, it is promising to use such films, possibly with a higher concentration of molybdenum or tungsten, as buffer layers between the membrane and the palladium layer.

\section{ACKNOWLEDGEMENT}

The work was carried out within the framework of the grant of the Ministry of Education and Science of the Republic of Kazakhstan on the subject: No. 1628 / GF4 "Development of hydrogen permeable membranes based on niobium and tantalum alloys characterized by high performance indicators".

\section{REFERENCES}

[1] A.I. Livshits, M.E. Notkin and A.A. Samartsev, "Physico-chemical origin of superpermeability - large-scale effects of surface chemistry on «hot» hydrogen permeation and absorption in metals". J. Nucl. Mater. vol. 170. pp. 74-94, 1990 .

[2] A. Livshits, F. Sube, M. Notkin, M. Soloviev, M. Bacal, "Plasma driven suprerpermeation of hydrogen through group Va metals", J. Appl. Phys. vol. 84. pp. 2558-2564, 1998.

[3] A. Busnyuk, Y. Nakamura, Y. Nakahara et al. "Membrane bias effects on plasma-driven permeation of hydrogen through niobium membrane". J. Nucl. Mater. vol. 290-293, pp. 57-60, 2001
[4] Y. Hatano, K. Watanabe, A. Livshits et al. "Effects of bulk impurity concentration on the reactivity of metal surface: Sticking of hydrogen molecules and atoms to polycrystalline $\mathrm{Nb}$ containing oxygen". J. Chem. Phys. vol. 127. pp. 204707-1-13, 2007.

[5] K. Gaseund, Metallen/Ed. By E. Fromm, E. Gebhardt. Berlin: Springer, 1976, pp. 747

[6] A.C. Makrides, M.A. Wright and D.N. Jewett, Separation of Hydrogen by Permeation. US Patent 3350845.1967.

[7] C. Nishimura, M. Komaki, M. Amano, "Hydrogen Permeation Characteristics of Vanadium-Nickel Alloys". Mater. Trans.. JIM. (The Japan Institute of Metals) vol. 32, no. 5, pp. 501-507, 1991.

[8] M. Amano, M. Komaki and C. Nishimura, "Hydrogen permeation characteristics of palladium-plated V-Ni alloy membranes". J. LessCommon. Met. vol. 172-174, pp. 727-731, 1991.

[9] R.E. Buxbaum and T.L. Marker, "Hydrogen transport through nonporous membranes of palladium coated niobium, tantalum and vanadium”. J. Membr. Sci. vol. 85, pp. 29-38, 1993.

[10] D.J. Edlund, D. Friesen, B. Johnson and W. Pledger, "Hydrogenpermeable metal membranes for high-temperature gas separations". Gas Separat. Purif. vol. 8, pp. 131-136, 1994.

[11] D.J. Edlund, J. Mc Carthy, "The relationship between intermetallic diffusion and flux decline in composite-metal membranes: implications for achieving long membrane lifetime". J. Membr. Sci. vol. 107, pp. 147-153, 1995.

[12] N.M. Peachey, R.C. Snow and R.C. Dye, "Composite Pd/Ta metal membranes for hydrogen separation". J. Membr. Sci. vol. 111, pp. 123 133, 1996.

[13] T.S. Moss, N.M. Peachey, R.C. Show and R.C. Dye, "Multilayer metal membranes for hydrogen separation". Int. J. Hydr. Energ. vol. 23, no. 2, pp. 99-106, 1998.

[14] R.E. Buxbaum and A.B. Kinney, "Hydrogen transport through tubular membranes of palladium-coated tantalum and niobium”. Ind. Eng. Chem. Res. vol. 35, pp. 530-537, 1996.

[15] A.V. Panichkin, A.M. Derbissalin, A.T. Imbarova, D.M. Dzhumabekov and Zh.Zh. Alibekov, "Corrosion resistance of hydrogen permeable membranes based on niobium and tantalum foils on the surface of which layers of solid solutions are formed". International Scientific Conference Industry 4.0, December 12-15, 2016, Borovets, Bulgaria, 2016, pp. 142145.

[16] A.V. Panichkin, A.M. Derbissalin, A.T. Imbarova, D.M. Dzhumabekov and $\mathrm{Zh.Zh}$. Alibekov, "Improvement of methodology and equipment for determination of hydrogen performance of thin flat metallic membranes" Complex use of mineral resourses. 2017, no. 2, pp. 46-53.

[17] A.V. Panichkin, A.M. Derbissalin, A.A. Mamaeva, D.M. Dzhumabekov and A.T. Imbarova, "Hydrogen permeability of membranes based on foil niobium and tantalum in the atmosphere of technical purity hydrogen". Complex use of mineral resourses. 2017, no. 3, pp. 42-47 